\title{
Factors Affecting Use of Social Media by University Students: A Study at Wuhan University of China
}

\author{
A.W.V. Athukorala ${ }^{1}$
}

\begin{abstract}
Social media platforms are very common in modern education system everywhere, especially in Chinese universities. The purpose of this paper was to identify the behavior of use of social media by students at Wuhan University in China. In order to investigate the concerns of students in using social media in relation to personal context, the study was carried out. Major concerns of students in using social media can be categorized into two types of phenomena; socio-economic factors and demographic factors. Accordingly, the research focused on eight socio-economic and political factors related to the use of social media and factors are affecting international students' and local students' cognition of social media. Random sampling methods was utilized for selecting the participants. The questionnaires were distributed among international and local students and 425 responses were received. The 216 international students and 209 Chinese students responded with an effective recovery rate of $86.4 \%$ and $83.6 \%$, respectively from each group. The results of the current study endorse a number of previous studies which examine different influencing factors in the use of social media. The research found that there is a huge impact of affecting factors on the use of social media by local as well as international students. Although, all factors mentioned; legal risk etc. seem to have affected both groups of students very effectively. Some factors seemed prominent among local students and some others seemed prominent among international students. On the whole, it was proved by the result that there was a significant influence of all factors on the use of social media. The main concerns in using social media are privacy and convenience. On the contrary, copyright and legal issues are often ignored by both international and local students. The level of concern is affected by the number of years of living abroad, local language proficiency, study level and experience. Among the variables, social media experience obviously inflecting the levels of all related influencing factors. As international students and local students depend heavily on social media for their
\end{abstract}

1 Senior Assistant Librarian, Sripalee Campus, University of Colombo. Email: watsalaa@yahoo.com, (D) https://orcid.org/0000-0002-2826-4310

Received: 29 November 2017, Accepted revised version: 21 March 2018. 
learning, research needs as well as their daily life in today's digital environment, it is important for university administrators to integrate media literacy education into academic training and professional development programs for both international students and faculty.

Keywords: China, Chinese language, International students, Legal risk, Privacy, Social media, Wuhan University 


\section{Introduction}

Consequent to the rapid development of Chinese education, Chinese student's enrollments of higher education have increased. In the past decades, China has made noticeable progress in the education sector, with regard to increased immigration of international students (Nzivo \& Chuanfu, 2013). It is worth mentioning that, every year Chinese Scholarship Council (CSC) awards a number of scholarships to the international students worldwide. On the other hand, most of the international students enroll in the Chinese universities to peruse their higher studies or study Chinese language as self-financial students. According to the CSC data China has become a leading country in Asia to receive international students with 6\% of the total international mobility. In 2012, China fetched 328,330 international students from different countries to study in the best higher education institutions in China. Insufficient English language proficiency limits the ability of international students to be fully involved in learning, as well as adjust to different dialect of local tutors. Understanding local language helps international students to interact with local students and to better understand local culture (Mahmud, Amata, Rahmana, \& Ishaka, 2010). Competency in the local language helps international students to start social interaction with university staff and faculty members, and also to settle down at their new places. On the other hand, failure to interact with local people may cause cultural shocks and miscommunication which can lead to lack of social support (Chen, 2011).

Social media platforms are very common in modern education system in Chinese universities. Kaplan and Haenlein (2010) have defined the concept of social media as "a group of internet-based applications that build on the ideological and technological foundations of web 2.0 and that allow creation and exchange of user generated contents". Social media can be considered as an information technology platform in which user communities can search their network, post the experiences and construct the relationships for varies reasons (Jiao, Geo, \& Yans, 2015). Researchers have viewed social media as an incorporated tool with a number of websites and application tools.

Technological improvements have greatly influenced university students all over the world. Additionally, shift from the conventional handling systems has brought changes in attitudes of students and behaviors regarding 
information seeking and using. Availability of computers with related hardware and software features and faster Internet connections have made a convenient and easily accessible service to the social media for many university students in the world. In addition to that, social media have become more integrated in to the host culture during their adaptation and to maintain connections to their home countries (Sawyer, 2011).

Most of university students use social media networks as an instrument to disseminate information and to communicate. They use and apply social media tools in their academic and research works and their leisure time engagements. According to Walsh (2008), blogging in China is not just a pastime for opinion leaders but a form of collective behavior emphasizing the cultural need of togetherness in the Chinese society (Walsh 2008). Falahah and Rosmala argued that the phenomenon of social networking access also occurred in higher education environment despite the debate about negative assumption of social networking impact on productivities, some of campus elements such as students or lecturers using these sites to disseminate information and Support the communication among them (Falahah \& Rosmala, 2011).

According to above discussion more and more data and literature need to understand real situation of how to ensure successful social adjustment to university students in the university environment by using of social media. And also time has come to identify some important concern factors which are barriers to use of social media. Future researches should continue to explore the impact that social media on students' adjustment to college both in terms of their social adjustment and other adjustment characteristics not captured in previous survey data. The present research expects to analyze these drawbacks and then filling the gaps of the social media studies. This study creates an innovative influence for literature on use of social media usage of university students in China where researches are still in its primary stage. This will provide guidance for researchers to identify the research gap which they can trace on their future studies.

Literature related to the social media, especially of Chinese and international students reveal that there is inadequate literature on the factors that influence 
to use social media in university students in Chinese universities. Kwon and Wen (2009) have discussed how individual differences affect users' intentions to use social network services. They have highlighted altruism and social identity as an important social factors their encouragements of use of social network sites. Lin, Li, Califf, and Featherman (2013) discussed factors affecting users' attraction to social network sites. Their research findings show that enjoinment is the most influenced factor in people's continued use of social network sites, followed by number of peers and usefulness. Some researchers have identified six different significant factors that effect on users' perceptions about quality in the context of social networking websites. They are namely efficiency, entertainment, community divineness, privacy, user friendliness, efficiency and navigability (Ell \& Bokhari, 2013). Sago (2015) had done a research on factors influencing social media adoption and frequency use. He discussed the positive relationship between the user enjoinment and perceived usefulness of the social media service and frequency of use. However, some researchers' ague that perceived usefulness, perceived ease of use, members, and compatibility have a positive significant effect on the actual use of the social network sites (Lee \& Sub, 2011). However, China is known for the huge population of Internet users and the stringent regulation on the use of the Internet. College students are an important component of Chinese Internet users and they have been criticized for egoism, materialism, declining commitment to social responsibility and spending too much time on SNS websites (Zhong, 2014). Further, researchers have emphasized Social Network (SN) had shown their rapid growth among students engaged in higher education where the most users are at young age and "digital native". According to this trend, students as well as lecturers have adopted this opportunity to support their academic activity in official or unofficial way. (Falahaha \& Rosmala, 2011). They further explained that the usage of social media in higher education can vary from marketing media, information media, communication media, and feedback, complain, announcement, sharing, task assignment and examination. The intensity of SN media usage depends of some factor such as: the background and behavior of user; university policy on Internet access; the behavior of university communication, the role and rule of SN in daily communication and the attitude of user. Many researches related to the social media and university students have focused to discuss functionalistic 
approach. The same arguments made by the Roblyer, McDaniel, Webb, Harmer, and Witty (2010) have discussed Social Networking Site (SNS) such as Facebook is one of the latest examples of communications technologies that have been widely-adopted by students and, consequently, have the potential to become a valuable resource to support their educational communications and collaborations with faculty (Roblyer et al., 2010).

Social media have become more integrated in to the host culture during their adaptation and to maintain connections to their home countries (Sawyer, 2011). Sawyer argues that new social media has brought people from different cultures together in the "global village". During the intercultural adaptation, people use social media to learn about their host countries, establish and maintain relationship and stay informed with events in their home countries (Sawyer, 2011). Further Sawyer, (2011) in his research on the impact of new social media on intercultural adaptation, explain that social media has a social, physical, and cultural influence on intercultural adaptation. Hall (1976), explained that different cultures will express different information needs depending on how reliant they are on the information contained in the context. Rosen, Carrier, and Cheever (2010) argued that there are differences in the way that people who identify with different cultures, based on both national identity and gender, manage their communication behavior within social network sites (Rosen et.al, 2010). Boyd and Ellison (2007) explained that social media are about two things; there are communication and networking. This argument is clear that because social media are two way communications by it is nature. Correa, Hinsley, and Zunigo (2010) described that with millions of users worldwide use online social media tools in their interaction with others. Two scholars, Pai and Arnott, have also argued that, social network sites attract users seeking interpersonal interactions with their existing friends and colleagues, and mutually interesting content results when they share personal details and day to day experience (Pai \& Arnott, 2012). Chen and Starosta (1996) explained that only through global communication competence can people from different cultures communicate effectively and productively in the globalizing society (Chen \& Starosta, 1996). According to the above literature two things can be highlighted. There are a few research of social media based on analysis to multicultural perspective and most of social media studies based discuss on social networks sites. However Social media 
is broad concept and, social networks sites are one part of its category (Kaplan \& Haenlein, 2010).

Many researches have shown that social adjustment plays a critical role in student persistence at college. Social media such as Facebook, used widely by this population, have the potential to positively enhance students' transition to college by encouraging connection and interaction among peers. Gray, Vitak, Easton and Ellison (2013) examine the role of Facebook in students' social adjustment during their first year of college education. They conducted a survey among students in a Private Liberal Arts College in Midwest. Their results indicated positive relationships between two Facebook variables: first relationship is the number of Facebook Friends at the college and their engagement in collaborative behaviors with classmates through the sited and measures of social support and social adjustment; Second positive relationship between social adjustment and persistence at the university. Further they explained that today's generation of students enters the college environment with access to social media tools offering communication affordances that may prove beneficial for the adjustment process. Social media including social network sites, personal blogs, and geographically bounded discussion forums may ease students' transition from high school to college by providing them with informational and social support as well as a way to find and connect with other students (Gray et al., 2013). Most of the researchers state that Facebook is the site most embedded in the lives of U.S. college students (Hargittai, 2007; Ellison, Steinfield, \& Lampe, 2007). Above studies emphasized that social media represent a powerful avenue through which students can connect with their peers at the institution and thus adjust more easily to college life. More recent research shows that connecting with other students online is an important aspect of the socialization process in college (Heiberger \& Harper, 2008). However, these studies have not explained the other factors that influence the use of social media. Therefore, this research expects to fill the gap of previous studies.

Although some studies have been conducted related to the international students and Chinese students in China, it appears that there is an inadequate research literature available related to the social media behavior of international and local university student's issues. Although Chinese and 
international students live in the same culture, one party's intention and attitudes can be different from each other. On the other hand, Bruce and Ingried (2004) state that social interaction in organizations is commonly motivated by one party's intention to influence another's attitudes, beliefs and or behaviors. Therefore, this research is expected to examine the problem that how the different factors influence the use of social media in multicultural university students from different parts of the world.

\section{Research Objectives}

The objectives of this study were to:

i Investigate what university students concern when using social media

ii. Explore the demographic characteristics of students that concern

iii. Identify what the correlation with personal context

\section{Methodology}

A survey method was used to collect data. The sample was selected from individuals studying in Wuhan University in China. Wuhan University is one of the best universities in China offering wide range of disciplines to local as well as international students. Random sampling method was used collect data. A questionnaire was designed for Chinese students as well as international students in the Wuhan University. The questionnaire was designed mainly with structured, close-ended and, open-ended questions, multiple choice questions and attitude scales to obtained necessary information to satisfy the objective of the study. Structured close ended types are used as they are normally characterized by a group of fixed responses and respondents are allowed to choose one or more responses that are designed to reflect various views. An attitudinal scale was designed to obtain a variety of opinions about attitudes. Open-ended questions are formulated to allow respondents to express their views freely. The questionnaires were randomly distributed among local students and international students.

The descriptive data analysis was carried out to analyze eight influencing factors. The Statistical Package of Social Sciences (SPSS) software and Microsoft Excel package were used to analyze the data. The results are presented with frequencies, percentages and mean values. 


\section{Results}

Among valid responses: 216 responses received from international students and 209 responses received Chinese students. Effective recovery rate was $86.4 \%$ and $83.6 \%$, respectively. A complete inspection of the questionnaires of the international students shows that $57.52 \%$ of the students were from Asian countries while 25.91\% were from the European countries. $16.57 \%$ were from the African countries. Their language distribution indicates that 16.66\% use French as their native language, 13.42\% Korean, 13.8\% English, 4.62\% Russian, 4.62\% Hindi, 5.55\% Thai, 6.48\% Vietnam, 4.62\% Urdu, 3.24\% Portuguese, 2.31\% German, 1.85\% Italian, 1.85\% Bangla, 4.62\% Nepal, 2.31\% Sinhala, 2.77\% Malagasy, 1.85\% Spanish,4.16\% Kazakh, 1.85\% Arabic and 0.92\% Tamil.

\section{Response to Eight Factors}

The present study is attempted to identify the factors affecting the use of social media. Therefore, this data analysis presents the factors that affect the use of social media web sites. Legal risk, privacy, credibility, convenience, copyright, cost, time and permanency are concerned. Statistics prove that both international and local students have shown a certain degree of concern on all above influencing factors of use of social media (Figure 1).

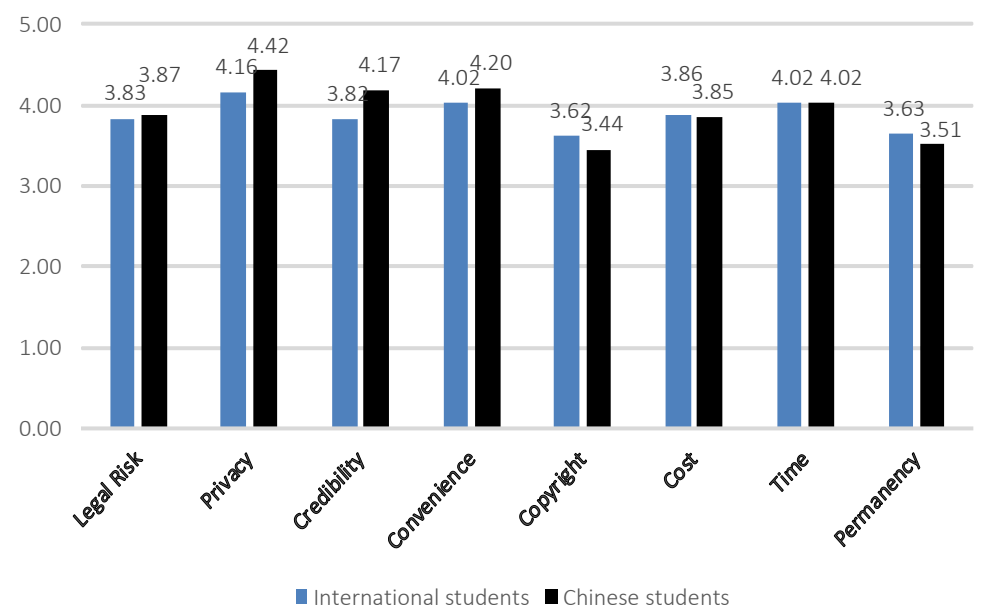

Figure 1. Response to eight factors 
Based on their importance, average values obtained for the factors are depicted in Figure 2. Data proved that factors considered in the use of social media by international students according to the sequence of importance are privacy, convenience, time, cost, legal risk, credibility, permanency and copyright, while ranking of these factors by Chinese students are privacy, convenience, credibility, time, legal risk, cost, permanency and copyright.

Regardless of the influence of variables, privacy and convenience are always listed as top concerns, and they are the most important influencing factors for international students. Therefore, privacy and convenience have become common important factors affecting both international students and Chinese students.

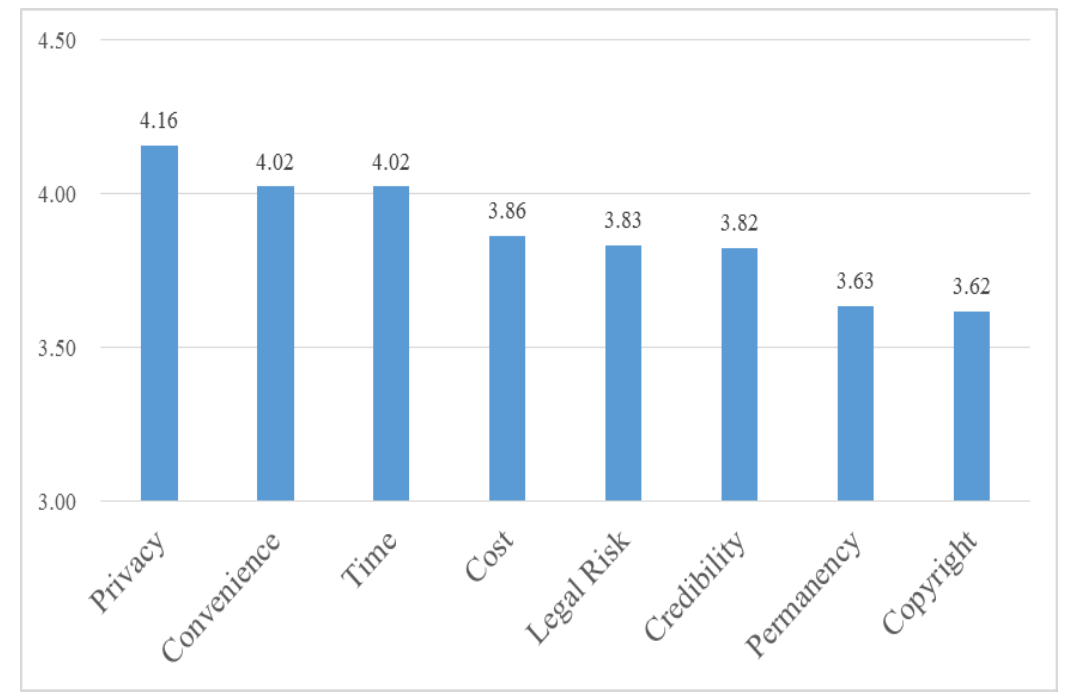

Figure 2. Average values obtained after assignment to eight factors

Although the factors of cost, permanency and copyright are ranked higher among international students than local ones, their degree of attention are not the same for the two groups of students. In contrast, in addition to copyright and cost factors, Chinese students pay more attention to other factors than international students. Finally, the cognition on the privacy and credibility of social media are quite different among the two groups. 


\section{Legal Risk}

Figure 3 demonstrates that the surveyed sample of students is more concerned about legal risk when they used social media. Correspondingly, $27.31 \%$ of the total samples of Chinese students have mentioned that legal risk is the most crucial factor affecting the use of social media while international students have claimed it at $26.32 \%$. However, $1.91 \%$ of the total sample has specified that legal risk is an absolutely insignificant factor in the use of social media. The same attitude has been highlighted by $2.78 \%$ of the international students. According to the results, it shows that both Chinese and international students are greatly concerned about the legal risk. However, in both groups, the least number of students thinks that legal risks and issues may result in hindering the use social media. Although social media like Facebook, Twitter, LinkedIn, blogs, wikis, and other virtual communities provide new opportunity to build up stronger relationships among users, there are many inherent legal risks that everyone has to face practically. Results reveals that $6.48 \%$ of the Chinese students and $7.66 \%$ international students do not care about the legal risk when they use the social media in different communication networks.

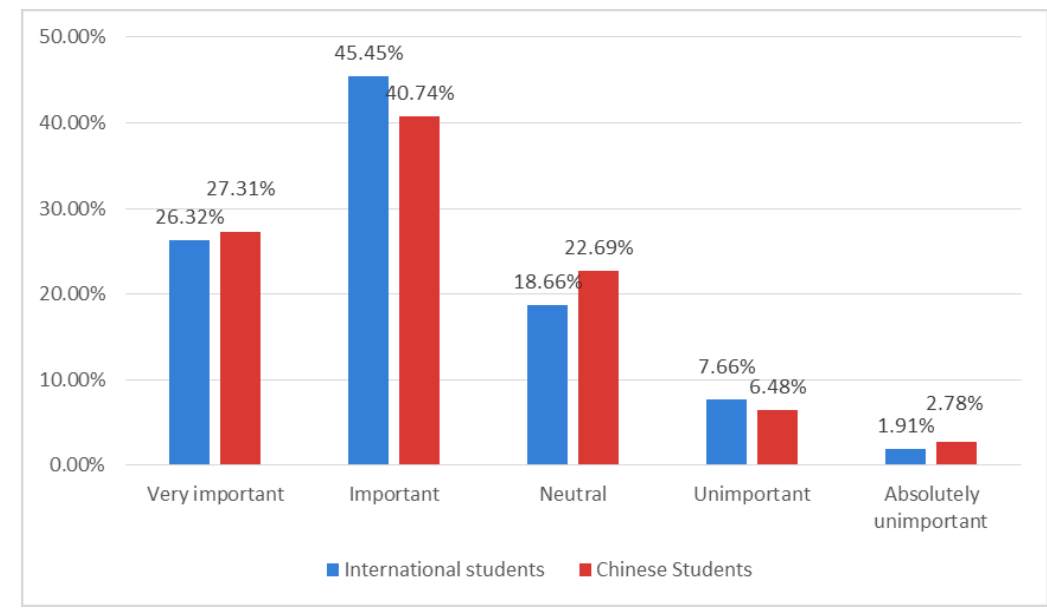

Figure 3. Importance of legal risk

\section{Privacy}

According to Figure 4, majority of Chinese students (53.11\%), pointed out that privacy is very important factor, when they use social media. Further $44.91 \%$ of the international students also stated the same idea. Sheehan and Hoy (1999) have found that as individuals concerned about privacy increase, 
the frequency with which they register decrease in web sites. Cha (2010) has mentioned there is a relationship between privacy concerns and the use of social networking web sites. This idea can be further highlighted with the percentage of students responded "absolutely unimportant". Only a limited portion of $0.47 \%$ of Chinese students and $1.39 \%$ of international students of the sample have mentioned privacy is absolutely unimportant. When comparing with international students, Chinese students are more concerned about the privacy. The results related to the other categories ("unimportant", "neutral") also reveals that privacy is the most important factor to affect the use of social media. Further, it reveals that most of the Chinese and international students are aware that personally and legally they are responsible for everything that they post online.

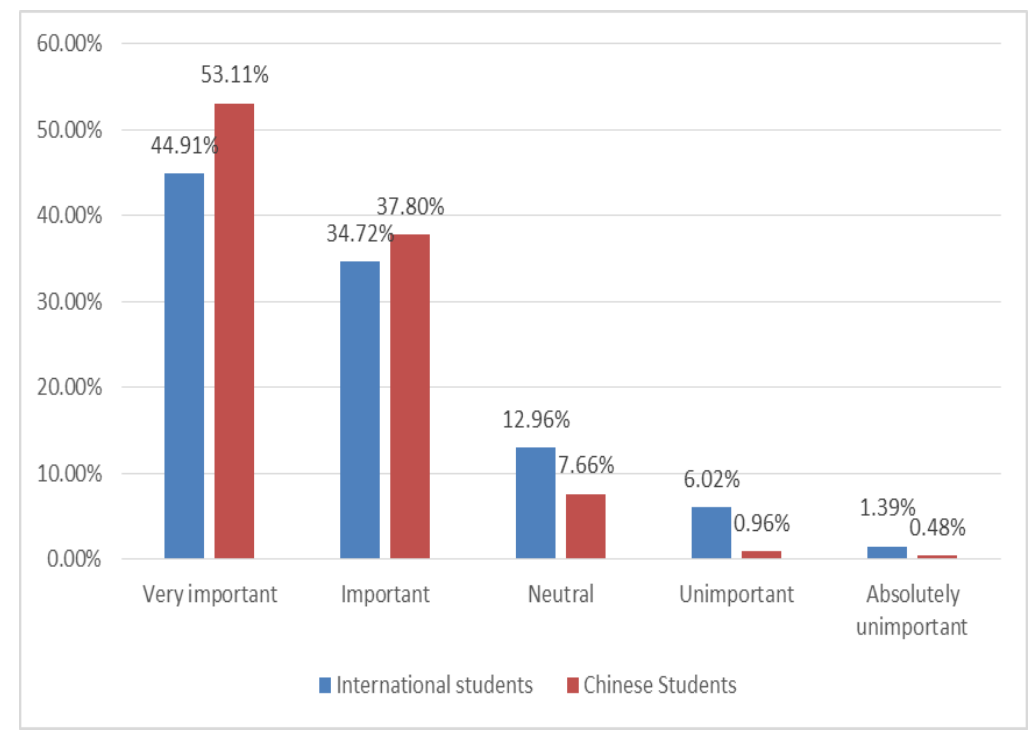

Figure 4. Importance of privacy

\section{Credibility}

This paper also seeks to understand how users determine the credibility of social media, which can be defined as the believability of a source or message. Flannigan and Metzger (2007) stated that this is made up of two primary dimensions namely, trust worthiness and expertise. Figure 5 shows that $41.63 \%$ of Chinese students surveyed are concerned about the credibility of social media, and $38.89 \%$ for international students. It reveals that most of the university students expect to discover reliable information from the social 
media. A reasonable number of the Chinese students (39.23\%) and international students (25.93\%) are concerned that this is a very important factor. Taking into consideration all of above data it shows that, compared to Chinese students, international students are more concerned about the credibility of the social media. No Chinese students mentioned credibility as an absolutely unimportant factor while $0.93 \%$ of the international students' claimed that it is an absolutely unimportant factor. However, recent researchers highlighted that there should be a mechanism to measure the credibility of the information which is provided by social media.

\section{Convenience}

With regard to convenience, respondents have pointed out how convenience influence to the use of social media (Figure 6). Responses from both Chinese and international students indicated convenience is important in the use of social media: $47 \%$ of Chinese students and $38.89 \%$ of international students.

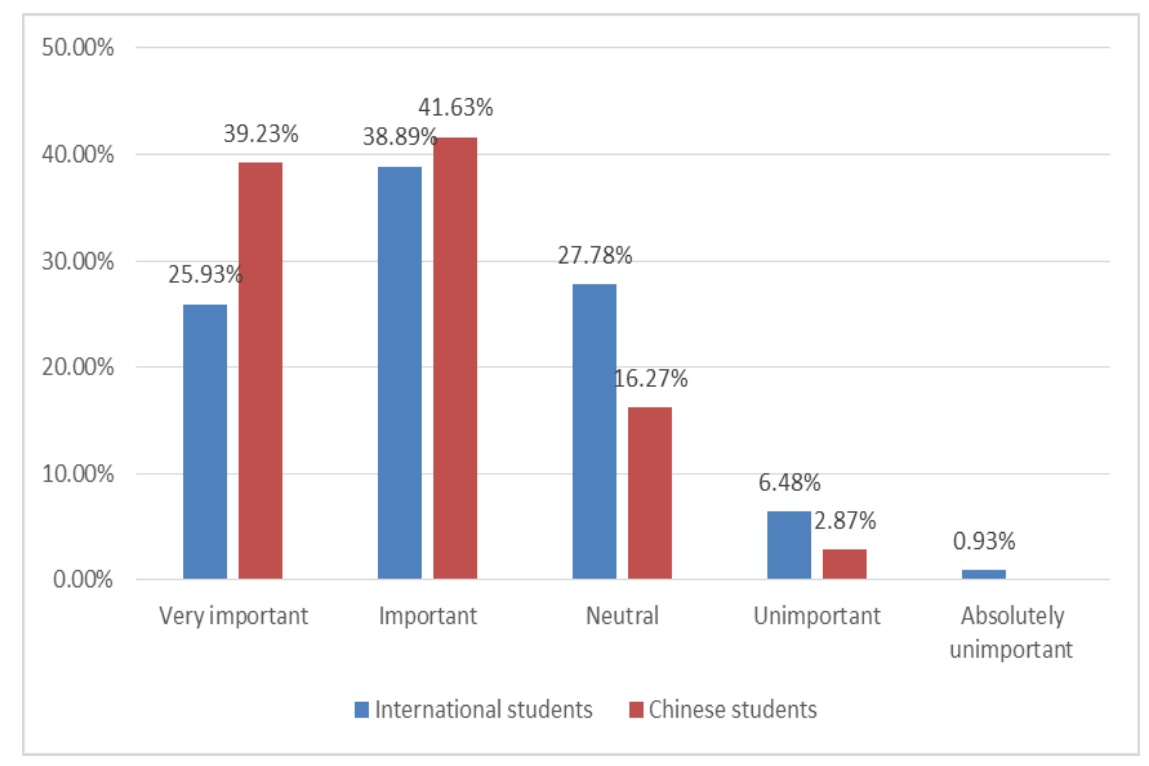

Figure 5. Importance of credibility

The next highest number of the respondents (Chinese students 39\% while international students $35.65 \%$ ) have indicated that convenience is an important factor that affects the use of social media. Figure 6 shows that the highest number of both the samples considered convenience as the most influential factor for the use of social media among college students. Chinese 
students claimed Absolutely Unimportant 0.48\%, Unimportant 3.37\%, while international students claimed $2.31 \%$ as absolutely unimportant and $3.24 \%$ as unimportant.

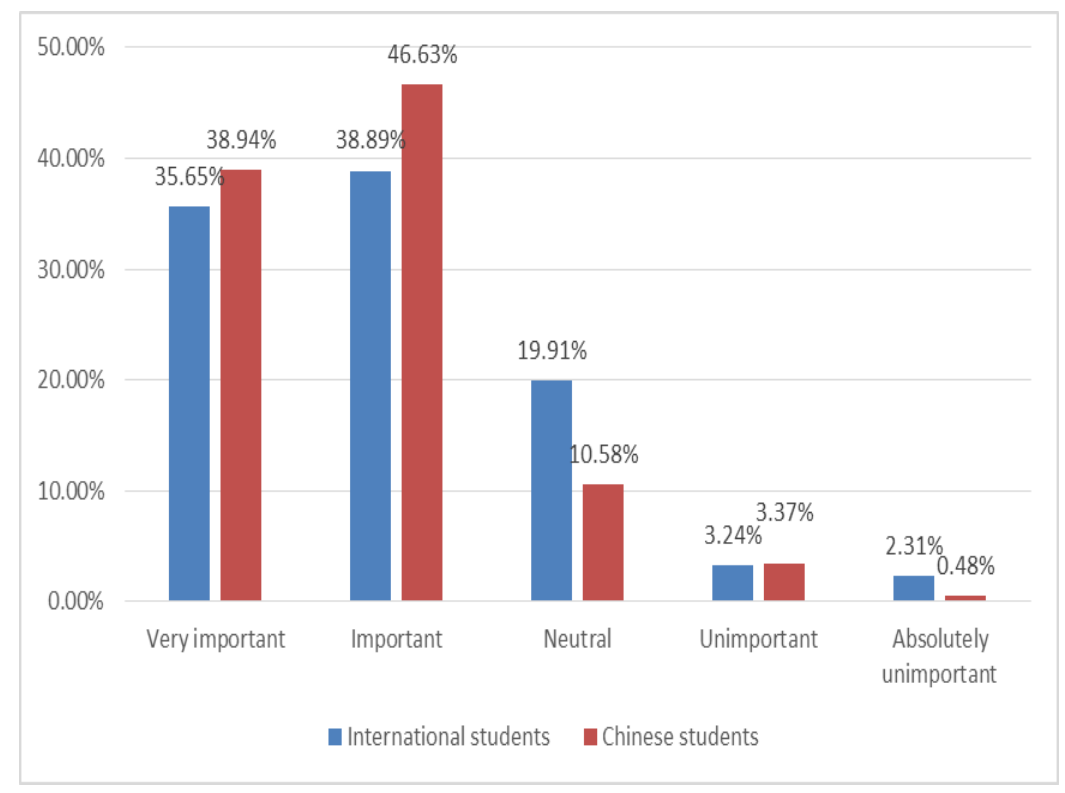

Figure 6. Importance of convenience

Davis, Bagozzi, and Warshaw (1997) found that both the factors of usefulness and enjoyment affect to the motivation to use a particular system of information technology.

\section{Copyright}

When inquired whether students pay attention to the copyright when they use social media, $34.39 \%$ of the Chinese respondents affirmed they considered it as an important factor, while international students (31.48 \%) claimed it as an important factor. Reasonable number of Chinese respondents (13.88\%) and international respondents (12.50\%) of the sample has stated copyright as an unimportant factor influencing the use of social media. $12.92 \%$ of the Chinese respondents affirmed they consider it as a very important factor, while it is $25 \%$ for international students. Results are presented in Figure 7. 


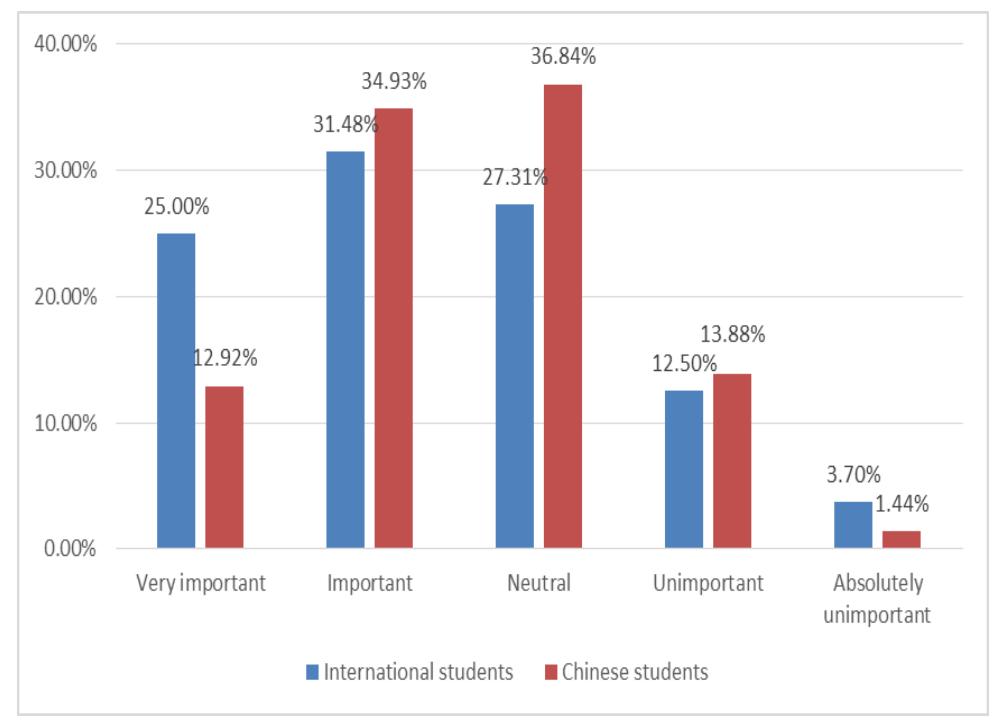

Figure 7. Importance of copyright

\section{Cost}

The results indicated that most students are concerned with, the factor of cost in using the social media: $26.79 \%$ of Chinese students and $29.17 \%$ of international students have mentioned that cost is a very important factor for them when they use social media (Figure 8). It is also obvious that the least number of Chinese students (0.95\%) and 1.39\% international students have stated that cost is an absolutely unimportant factor that they are concerned about using the social media.

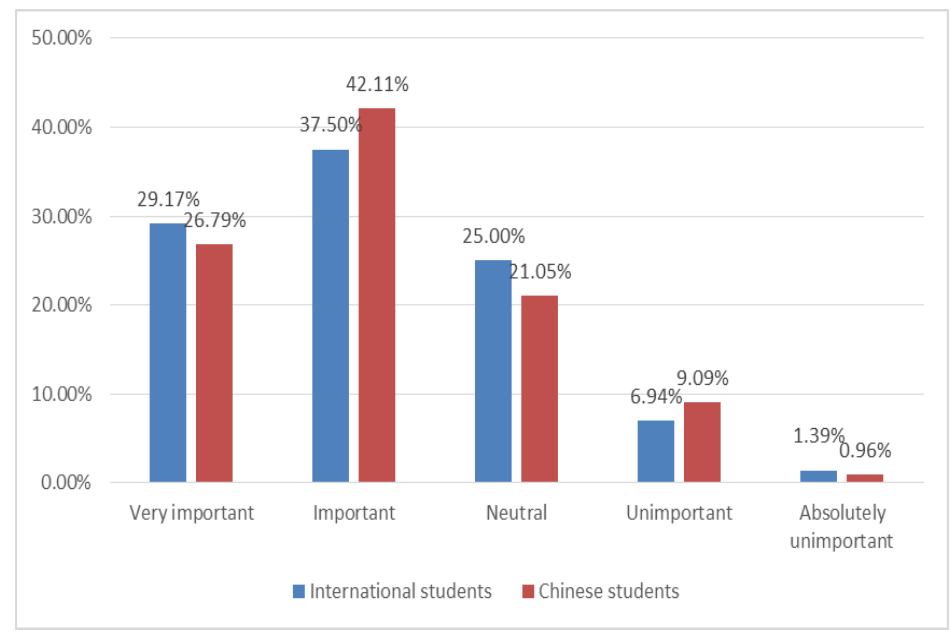

Figure 8. Importance of cost 


\section{Time}

Results revealed that most of the students are concerned about the time spent on the use of social media (Figure 9). $45.45 \%$ of Chinese students and $36.11 \%$ of the international students have agreed to it. $31.10 \%$ Chinese respondents and $37.50 \%$ of international students have claimed that the time is a very important factor that influences the use of social media. None of the Chinese students has claimed that time is absolutely unimportant, while the number of international students in that category is $1.39 \%$. This shows that most students are concerned that time is as an influential factor in the use of the social media.

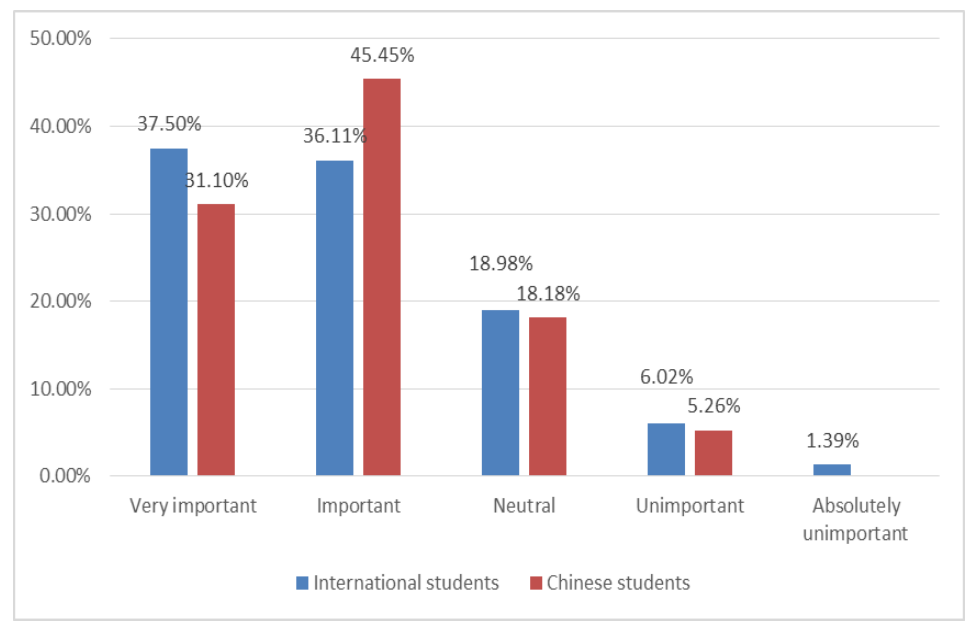

Figure 9. Importance of time

\section{Permanency}

In terms of permanency as a factor in using social media, $35.89 \%$ of the Chinese students sample and $33.80 \%$ of the international students sample have claimed that there is no idea about it. While $35.41 \%$ of the Chinese students and $38.43 \%$ international respondents claimed that permanency is important factor that influence use of social media; $15.31 \%$ of the Chinese students and $18.06 \%$ of the international students have mentioned that permanency is a very important factor the influence for the use of social media; $11.48 \%$ of the Chinese students and $8.33 \%$ international students have claimed that permanency is an unimportant factor (Figure 10). 


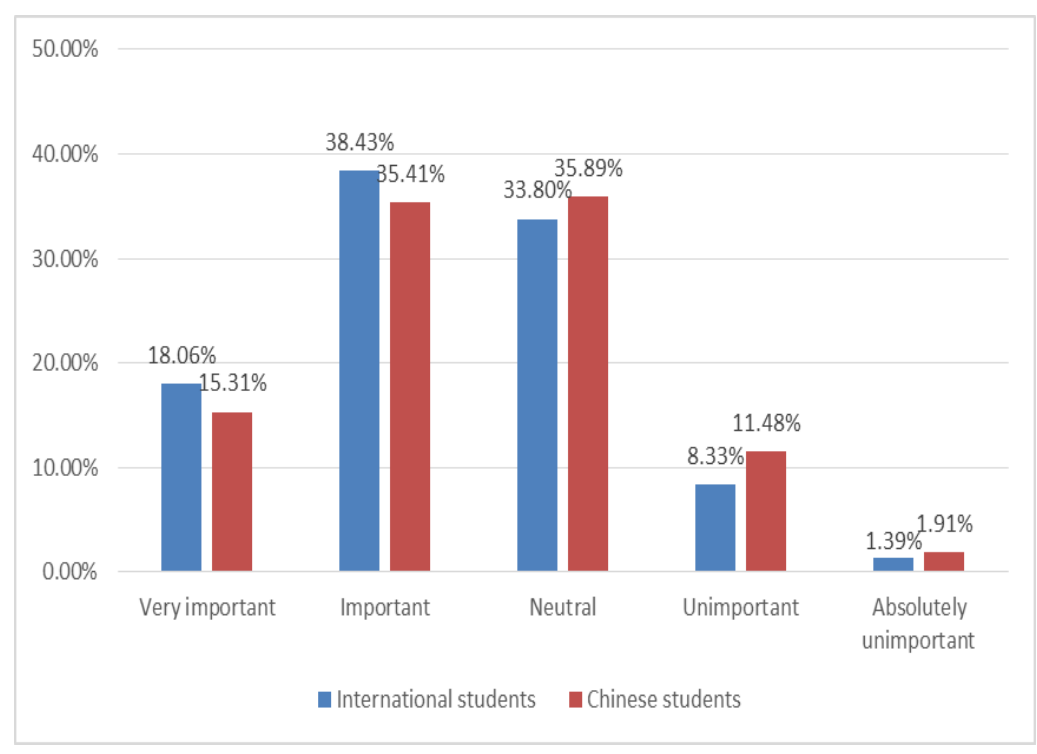

Figure 10. Importance of Permanency

Factors Affecting International Students' Cognition of Social Media The differences concerning social media usage may be linked to socioeconomic factors, such as host language proficiency, disciplinary backgrounds, study level, years of migration, or experience with social media. Good and bad perceptions of social media vary according to demographic and psychosocial characteristics (Keating, Hendy, \& Can, 2015).

\section{Host Language Proficiency}

Differences between international students' educational backgrounds and the educational systems in which they are enrolled may pose difficulties not encountered by domestic students (Leder \& Forgasz, 2004; Mostafa 2001). Many researchers have claimed that language barrier is one of the main problems facing students in a transnational environment.

Among international students, 69 respondents (31.9\%) have Chinese proficiency lower than the average, 76 people (35.2\%) are average, and 71 (32.9\%) are higher than average. Analysis shows that the cognition of different factors does not show a positive relationship with the improvement of Chinese proficiency. 


\section{Major Difference}

China has a huge demand for the technology savvy immigrant group Science, Technology, Engineering, Mathematics (STEM) education is largely based on the integration of all kinds of resources. Since social media as an innovative platform to encourage information exchange and cooperation is applied more and more to STEM education. Previous researches have shown significant differences in disciplines. Students in science and engineering tended to use wikis and Questions and Answers more often, and blogs and micro blogs less often, than students in humanities and social sciences. Humanities and Social Science students used online reviews more often than students in science and engineering (Kim, Sin, \& He, 2013). However, there is no sufficient research on international students' adoption of social media from the subject point of view.

In this research, 117 (56\%) of the respondents are from humanities and social sciences, 73 (34.9\%) from STEM, and 19 (9.1\%) from other areas. According to Figure 11, students of humanities and social sciences are concerned more with privacy, credibility, convenience and copyright than STEM students. While in terms of legal risk, cost, time, permanency, STEM students pay more attention than students of humanities and social sciences. This may be determined by the empirical characteristics of STEM disciplines, since empirical studies need to follow rigorous rules in science and mathematics, rather than imagination.

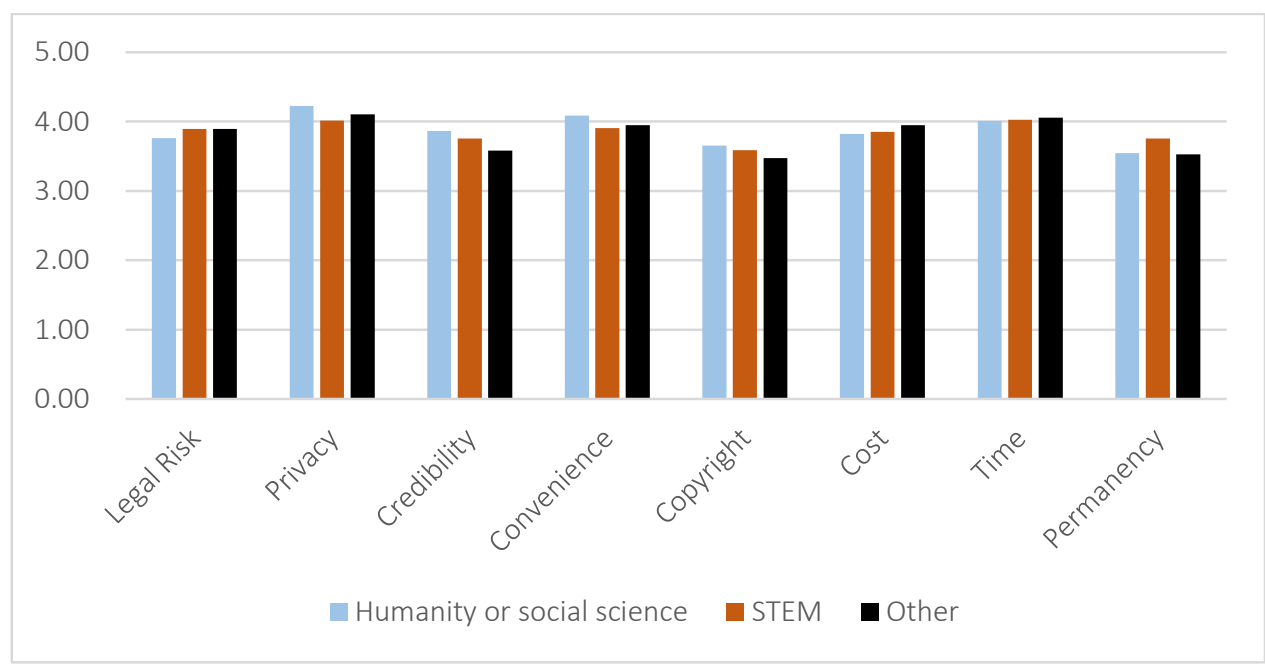

Figure 11. Major differences and eight influencing factors 


\section{Study Level}

Research investigated 103 undergraduate international students (47.9\%) (SL1), 58 master's students (27\%) (SL2), 41 doctoral and above (19.1\%) (SL3), and 13 international students involved in Chinese Language programmes (SL4).

As it can be seen in Figure 12, education affects the cognition of social media usage of international students. The factors that international undergraduates pay more attention than graduates are legal risks (3.88, $\mathrm{n}=103)$, copyright $(3.75, \mathrm{n}=103)$, time $(4.08, \mathrm{n}=103)$ and permanency (3.68, $\mathrm{n}=103)$. In contrast, graduate students concerned more on privacy (4.22, $\mathrm{n}=58)$, credibility $(3.88, \mathrm{n}=58)$, convenience $(4.26, \mathrm{n}=58)$ and cost (3.95, $\mathrm{n}=58$ ). As can be seen, in addition to legal risks and permanency, SL3 are concerned less on related issues of social media than SL1 and SL2. This may be due to the fact that professional researchers are not keen on social media; on the contrary, they pay more attention to the authoritative information sources. Through the comparison of cognition of SL1 and SL2, it is revealed that undergraduate international students focus more on legal risks, copyright and permanency than migrant students following Master's courses, on the issues of privacy, credibility, convenience, cost and time, but undergraduates are less concerned.

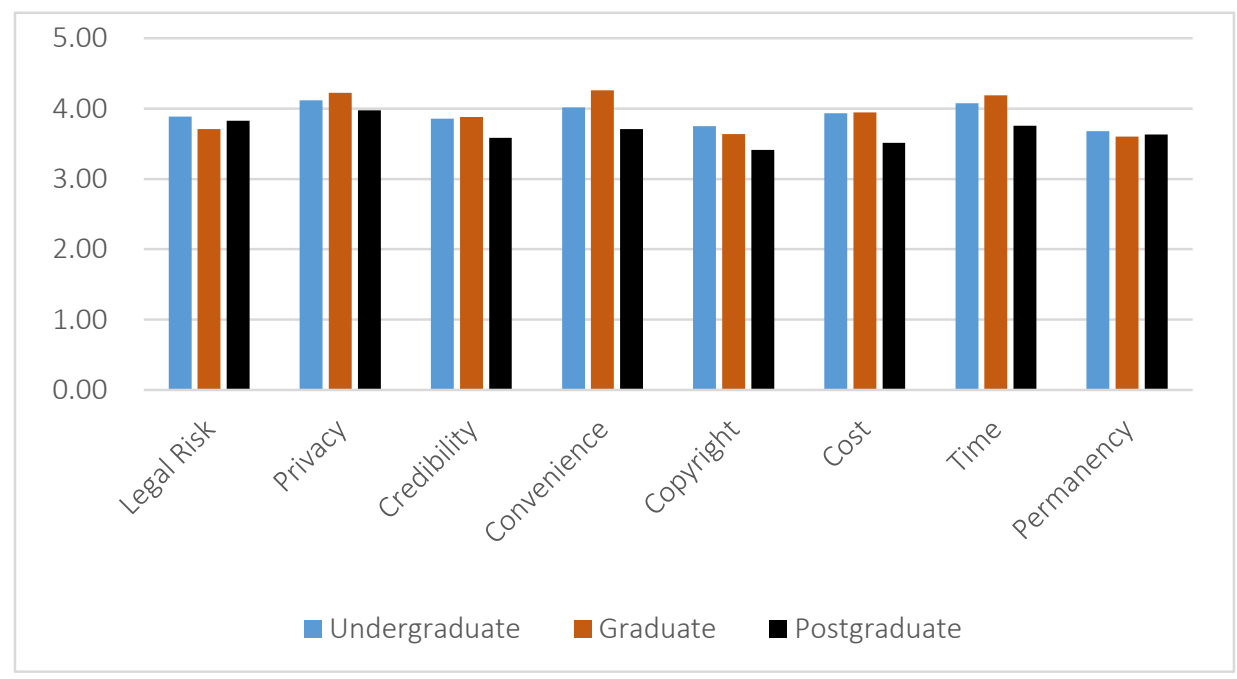

Figure 12. Study level and eight influencing factors 
Previous study showed that undergraduates were more likely to use SNS for Educator Licensure Information System (ELIS) than graduate students, which highlights some of the problems in the application of international students' social media usage. Undergraduate international students may be unable to grasp the use scales of social media, and spend a lot of time and energy on social media, ignoring the protection of their own interests and content evaluation, which leads to some negative consequences.

\section{Years of Living Abroad}

In survey sample, 151 people (69.9\%) have studied in China for 3 years or less (YLA1), 45 respondents for 3-4 years (20.8\%) (YLA 2), 20 people for 4 years or above $(9.3 \%)$ (YLA3). The length of years living abroad as the duration of influence of the local environment/culture on students was considered. Studying abroad for 4 years or more basically means the student has completed his or her bachelor's or master's degree, and has basically adapted to the local learning and lifestyle. After years of learning in a transnational environment, one has formed his value system, as well as his intercultural characteristics. 3 to 4 years of living abroad means that one has just completed language courses in preparation of further study, started professional learning, familiarized himself gradually with the local environment. Students who are living less than three years in abroad may or may not be completed their preliminary language course or sometimes, they are in the preparation stage for higher studies. While trying to adjust to the hot culture. The results are depicted in Figure 13.

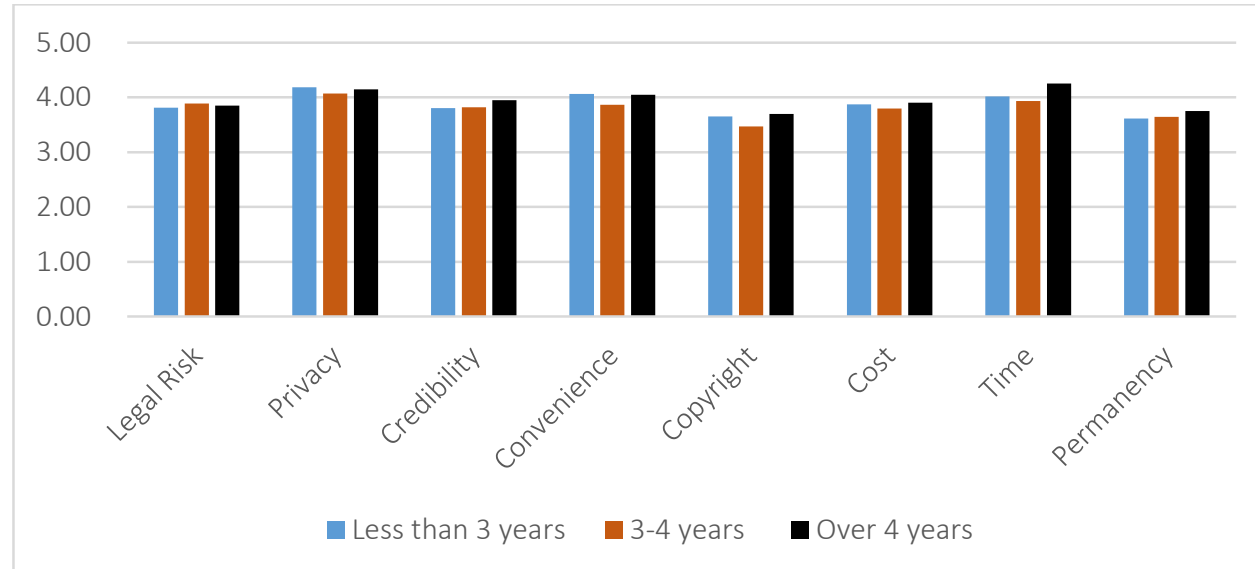

Fugure 13. Years of living abroad(YLA) and eight influencing factors 
YLA1 only pay privacy and convenience a higher level of attention. However, students who are experienced in more than four years (YLA4) in studying abroad, they more concern about credibility and permanency. Those who are studying in abroad 3-4 years (YLA3) pay more attention to credibility, copyright, cost, time, and permanency.

\section{Use Experience}

The experience of using social media affects international students' cognition of social media (Figure 14). The more experience they have with social media, the more attention they pay to risk factors. The cognition of factors for international students with above average use experience are much higher, namely, privacy (4.3, $\mathrm{n}=162)$, time (4.22, $\mathrm{n}=162)$, convenience (4.19, $n=162)$, cost $(3.97, n=162)$, credibility (3.97, $n=162)$, legal risks (3.95, $\mathrm{n}=162$ ), copyright (3.77, $\mathrm{n}=162$ ) and permanency (3.77, $\mathrm{n}=162$ ). However, those international students with under average experience are concerned the most about permanency $(2.89, \mathrm{n}=9)$ and cost $(2.56, \mathrm{n}=9)$, and they do not care about convenience (2.33, $\mathrm{n}=9)$ ). Only $9(4.2 \%)$ respondents' experience of social media is lower than average, 45 (27.8\%) are average, and 162 (75\%) are higher than average.

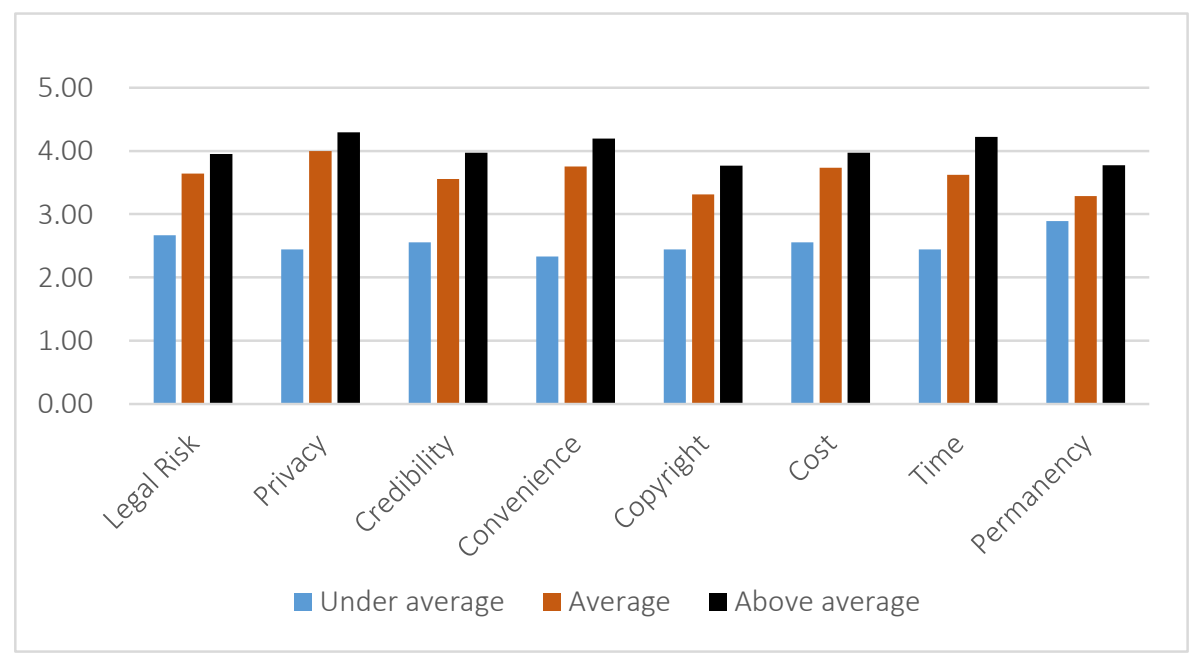

Figure 14 Use experience and eight influencing factors

Personal and professional use of social media is related to individual perceptions of social media (Moreno, Navarro, Tench., \& Zerfass, 2015) With the growth of social media use experience, international students pay 
more attention to the relevant issues, and the differences among different groups are significant. In the social media environment, experienced international students can obtain a priori knowledge through related services, directly applied to the current information services, to determine the relevant issues.

\section{Discussion}

The results of the current study endorse a number of previous studies which examine different influencing factors in the use of social media. The research found that there is a huge impact of affecting factors on the use of social media by local as well as international students. Although, all factors mentioned; legal risk etc. seem to have affected both groups of students very effectively, some factors seemed prominent among local students and some others seemed prominent among international students. On the whole, it was proved by the result that there was a significant influence of all factors on the use of social media. The main concerns in using social media are privacy and convenience. On the contrary, copyright and legal issues are often ignored by both international and local students. The level of concern is affected by the number of years of living abroad, local language proficiency, study level and experience. Among the variables, social media experience obviously inflecting the levels of all related influencing factors.

The Chinese education system (most universities) has established a mechanism to overcome the language issue by introducing Chinese language as a mandatory subject for international students. Language improvement efforts by international students help to facilitate their adaptation in the university environment. In our survey, English is not the mother tongue for many international respondents, and they use their own native languages. Therefore, it is an advantage for them to learn Chinese for their study and social affairs in the university. Meanwhile, it will be beneficial when they use social media. It can be concluded that socio-economic concerns were taken into consideration by the students based on the level of language proficiency. The research found that apart from the socio-economic factors, four other variables; Level of language proficiency, type of academic disciplines majored, Level of education attained, Length of the course and years of experience, to have a significant influence in the use of social media. The results showed that students' belonged to different types of 
majors had different type of socio-economic concerns when using social media. The study also found that the level of education students had achieved; undergraduate, graduate or post graduate qualification played a major role in deciding socio-economic concerns when international students facing social media. Similarly, length of stay, one year two year and so had major impact on socio-economic concern when students facing social media. Also, it was proved that the students with more experience had different concern to student with less experience in facing social media.

When discussing similarities and differences between local and international students in the use of social media, both groups seem to have shown significant differences between them. The research found that different groups have different concerns on socio-economic factors might be taken as support for the idea that international and local students have shown similarities and differences when facing these concerns. These similarities and differences seemed to have appeared due to the effects of all variables. The variables include Level of language proficiency, type of academic disciplines majored, Level of education attained, Length of the course and years of experience.

Both Chinese and international students are greatly concerned about the legal risk. However, only few students in both groups think that the legal risk and issues may have negative effect on one's social media use. Moreover, a substantial number of studies on social media and legal risks have claimed that online opportunities and risks are interconnected (Livingstone \& Haddon, 2009), which has been supported by the findings of the current research and concludes that the more university students are concerned about the legal risk, the less frequently they will use social media sites. This can be identified as a barrier in using social media by the Chinese and the international students. Both international and local student groups claim that convenience is one of the most important factors that affect the use of social media. Many researches have claimed that both usefulness and enjoinment factors affect the motivation in the use of information technology system (Davis, 1989).

Study reveals that compared to Chinese students, international students are more concerned with the credibility of the social media. This shows that most of the university students expect to discover reliable information from 
social media. However, Flanagin and Metzger (2000) state that people trust the Internet as a news source as much as other media, with the exception of news media. The research revealed that there is a correlation between use of social media and its credibility. Although, previous studies emphasize that social media have become more integrated into the host culture during their adaptation, the international students' expectation of highest amount of credibility of using social media may badly influence in establishing and maintaining relationships with their host culture. On the other hand, when Chinese students do not care about credibility of social media it increases the use of social media by local university students. This is a clear difference between Chinese and the international students.

When compared to international students, Chinese students are more concerned about the privacy of the social media. In the context of the social media, privacy is important because it helps increase trust in users, which can lead to increased use of social media sites. Some researchers have identified six different significant factors that effect on users' perceptions about quality in the context of social networking websites. Among six factors, they have named privacy as an important factor. On the other hand compared to the Chinese students, international students are more concerned about the copyright when they use social media. This means international students are more concerned about the rights of the authors and creators of works in the social media.

Research reveals that both groups of students have importantly concerned about time when they use social media. However, when compared to the International students, Chinese students are more concerned about time. This means international students are more likely to engage with the social media. On the findings of this study we can conclude that most students are addicted to the use of social media to escape from negative feelings, learn their host culture and continuing bond with their home country. Concerning other factors such as cost, both student groups are concerned about it as considerable factors that affect the use of social media. The three factors of cost, stability and copyright are ranked higher among international students than local students. 


\section{Conclusion and Recommendations}

Current research reveals factors affecting over differences and similarities of social Media, used by International and Chinese students. According to these differences and similarities adaptation behavior and social media usage of Chinese students and their identities are decided by their own individualities and the social economic factors of their own and host cultures. Finally, for international students, the use of social media to discover useful digital resources is an effective way to adjust themselves to the new learning and living environment. The major contributing factors for their use of social media are privacy, convenience and time spent. Based on this finding, social media providers should make improvements to protect user privacy. As international students depend heavily on social media for their learning, research needs as well as their daily life in today's digital environment, it is important for university administrators to integrate media literacy education into academic training and professional development programs for both international students and faculty. In addition, when media literacy education is provided, we also need to tailor it to people needs by paying attention to their differences in gender, age, discipline enrolled, country of origin, host language proficiency, and to help international students take advantage of the social media and to better protect their interests.

\section{References}

Boyd, D. M., \& Ellison, N. B. (2007). Social network sites: Definition, history, and scholarship. Journal of Computer-Mediated Communication, 13(1), 210-230.doi:10.1111/j.1083-6101.2007.00393

Bruce, B. \& Ingried, S. (2009). The medium and the message: The adaptive use of communication media in dynamic influence. Academic of Management Review, 29(2). 272-292. https://doi.org/10.2307/20159033

Charles N., Nzivo \& Chen C. (2013). International students perception of library services and information resources in Chinese academic libraries, The Journal of Academic Librarianship, 39(2), 129-137. https://doi.org/j.acalib.2012.11.004

Chen, G \& Starota, W. (1997) Intellectual communication competence: A synthesis communication year book, 19(1), 353-384. https://doi.org/10.1080123808985.1996.11678935 
Chen, G. M. (2011).Tweet this: use and gratifications Perspective on how active Twitter use gratifies a need to connect with others. Computers in Human Behavior, 27(2), 755-762.

Correa, T., Hinsley, A. W., \& de Zúñiga, H. G. (2010). Who interacts on theWeb?: The intersection of users' personality and social media use. Computers in Human Behavior, 26(2), 247-253. http://dx.doi.org/10.1016/j.chb.2009.09.003

Davis, F. D., Bagozzi, R., \& Warshaw, P. R. (1997). User acceptance of computer technology: A comparison of two theoretical models. Management Science, 35(8), 982-1003.

Ell, A. \& Bokhari, R. (2013). Key quality factors affecting users' perception of social networking websites. Journal of Retailing and Consumer Services 20. 120-129. http://doi.org/10.1016/j.jretconser.2012.10.013

Ellison, N. B., Steinfield, C., \& Lampe, C. (2007). The benefits of Facebook "friends:" Social capital and college students' use of online social network sites. Journal of Computer-Mediated Communication, 12(4), 1143-1168.

Falahah, S. \& Rosmala. D (2011).Study on social networking usage in higher education environment. Paper presented at the 3rd international conference on e-learning, ICEL - 2011. Retrieved from www.sciencedirect.com

Flanagin, A. J., \& Metzger, M. J. (2000). Perceptions of Internet information credibility. Journalism \& Mass Communication Quarterly, 77(3): 515540.

Gray, R., Vitak, J., Easton, E. W., \& Ellison, N. B. (2013). Examine social adjustment to college in the age of social media: Factors influencing successful transitions and persistence. Computers and Education, 67, 193-207. http//dx.doi.org/10.1016/j.compedu.2013.02.021

Halls, H. (2011). Relationship and role transformations in social media environments. The Electronic Library, 29(4), 421-428. http://doi.org/ 10.1108/02640471111156704

Hargittai, E., \& Walejko, G. (2007). The participation divide: Content creation and sharing in the digital age. Information, Communication \& Society, 11(2), 239-256. 
Heiberger, G., \& Harper, R. (2008). Have you facebooked Astin lately? Using technology to increase students involvement. New Directions of Student Services, 124, 19-38.

Jiao, Y. Gao, J. \& Yans, J. (2015). Social value and content value in social media: Two ways to flow. Journal of Advanced Management Science. 3(4), 299-306.

Kaplan, M. M. \& Haenlein, M. (2010). Users of the world, unite: The challenges and opportunities of social media. Business Horizons, 53, 5968. Retrieved from www.elsevier.cpm//locate/bushor

Keating, R. T., Hendy, H. M., \& Can, S. H. (2015). Demographic and psychosocial variables associated with good and bad perceptions of social media use. Computers in Human Behavior, 57, 93-98

Kim, K., Sin, S., \& He, Y. (2013) Information Seeking through social media: Impact of user characteristics on social media use. Retrieved from http://www.asis.org/asist2013/proceedings/submissions/posters/136poste r.pdf

Kwon, O. \& Wen, Y. (2009). An empirical study of the factors affecting social network service use. Computers in Human Behavior. 26. 254-263. https://doi.org/10.1016/j.chb.2009.04.011

Leder, G. \& Forgasz, H. (2004). Australian and international mature students: the daily challenges.

Higher Education Research and Development, 23(2), 183-198.

Lee, C. S., \& Sub, L. (2011). News sharing in social media: The effect of gratifications and prior experience. Computers in Human Behavior, 28, 331-339.

Lin, X., Li, Y., Califf, C. B., \& Featherman, M. (2013). Can social role theory explain gender differences in Facebook usage?. Paper presented at System sciences, HICSS $-2013,46^{\text {th }}$ Hawaii International conference of IEEE. http://doi.org/10.1109/HICSS.2013.125

Livingstone, S. and Haddon, L. (2009) EU kids online: Final report. Retrieved from http://eprints.lse.ac.uk/30130/1/Kids_online_introduction_(LSERO).pdf

Mahmud, Z., Amata, S., Rahmana, S., \& Ishaka, N. M. (2010). Challenges for international students in Malaysia: Culture, climate and care. 
Procardia Social and Behavioral Sciences, 7(C), 289-293. https://doi.org/10.1016/j.sbspro.2010.10.040

Moreno, A., Navarro, C., Tench, R., \& Zerfass, A. (2015). Does social media usage matter? An analysis of online practices and digital media perceptions of communication practitioners in Europe. Digital Publics, Public Relations Review, 41(2), 242-253.

Mostafa, G. (2001). (in Arabic) The problems of the international students in AlAzhar University: a field study. (Unpublished masters thesis). .AlAzhar University: Egypt.

Nzivo, C. \& Chuanfu, C. (2013). International students' pperception of library sservices and information resources in Chinese academic libraries. The Journal of Academic Librarianship, 39, 129-137. https://doi.org/10.1016/j.acalib.2012.11.004

Pai, P \& Arnott, D. (2012). User adaption of social networking sites: Electing use and gratifications through a means end approach. Computers in Human Behavior, 29(3) 1039-1053.

Roblyer, M. D., McDaniel, M., Webb, M., Herman, J., \& Witty, J. V. (2010). Findings on Facebook in higher education: A comparison of college faculty and student uses and perceptions of social networking sites. Internet and Higher Education, 13, 134-140.

Rosen, L. D., Carrier, L. M., \& Cheever, N. A. (2013). Facebook and texting made me do it: Media-induced task-switching while studying. Computers in Human Behavior, 29(3), 948-958.

Sago, B. (2015). A comparison of user perceptions and frequency of use of social media to use of social media. International Journal of Management and Marketing Research, 8(1), 15-29. Retrieved from https://papers.ssrn.com/sol3/papers.cfm?abstract_id=2655859

Sawyers. R(2011). The impact of new social media on intercultural adaptation: Honors Program at the University of Rhode Island.

Schmierbach, M., \& Oeldorf-Hirsch, A. (2012). A little bird told me, so I didn't believe it: Twitter, credibility, and issue perceptions. Communication Quarterly, 60(3), 317-337. 
Smith, H. Jeff., Milberg, S. J., \& Burke, S. J. (1996). Information privacy: Measuring individuals' concerns about organizational practices. MIS Quarterly, 20(2),167-196.

Walsh, M. (2008). The 10 habits of Asian media consumers, Asian-mediaconsumers-presentation Lankes, Retrieved from www.slideshare.net/mikewalsh/the-10-habits-of

Zhong, Z. J. (2014). Civic engagement among educated Chinese youth: The role of SNS, bounding and bridging social capital. Computers and Education, 75, 263-273. 